\title{
Energy-recycling pixel for active-matrix organic light-emitting diode display
}

\author{
Che-Yu Yang, Ting-Yi Cho, Yen-Yu Chen, Chih-Jen Yang, Chao-Yu Meng, \\ Chieh-Hung Yang, Po-Chuan Yang, Hsu-Yu Chang, Chun-Yuan Hsueh, Chung-Chih Wu, ${ }^{a)}$ \\ and Si-Chen Lee \\ Graduate Institute of Electronic Engineering, Department of Electrical Engineering, National Taiwan \\ University, Taipei, Taiwan 106, Republic of China \\ and Graduate Institute of Electro-Optical Engineering, National Taiwan University, Taipei, Taiwan 106, \\ Republic of China
}

(Received 17 January 2007; accepted 14 May 2007; published online 11 June 2007)

\begin{abstract}
The authors report a pixel structure for active-matrix organic light-emitting diode (OLED) displays that has a hydrogenated amorphous silicon solar cell inserted between the driving polycrystalline $\mathrm{Si}$ thin-film transistor and the pixel OLED. Such an active-matrix OLED pixel structure not only exhibits a reduced reflection (and thus improved contrast) compared to conventional OLEDs but also is capable of recycling both incident photon energies and internally generated OLED radiation. Such a feature of energy recycling may be of use for portable/mobile electronics, which are particularly power aware. (C) 2007 American Institute of Physics.
\end{abstract}

[DOI: $10.1063 / 1.2746960$ ]

Active-matrix organic light-emitting diode displays (AMOLEDs) have been considered to be a promising candidate for next-generation flat-panel displays due to various merits. ${ }^{1-3}$ Organic light-emitting diodes (OLEDs) in AMOLEDs, either bottom emitting or top emitting, in general, are composed of a reflective back electrode, 4,5 which would seriously degrade the contrast of an OLED display under a strong lighting environment. A few approaches have been used to reduce ambient-light reflection of OLEDs, ${ }^{6,7}$ including laminating polarizers or filters and adopting some black electrodes. For all these approaches, the incident ambient light and a large portion of the OLED emission are simply absorbed and wasted.

Such wasted photon energies may be recycled by placing a solar cell in the back of an OLED. With such a structure, the incident ambient light can be absorbed by the solar cell, thus reducing the reflection and giving higher contrast. However, the absorbed ambient light and the OLED emission can now be converted to useful electrical power. Such a feature of energy recycling may be of use for portable/mobile electronics, since such devices typically are very power aware. In this letter, we report an AMOLED pixel that has a hydrogenated amorphous silicon $(a-\mathrm{Si}: \mathrm{H})$ solar cell inserted between the driving polycrystalline silicon thin-film transistor (poly-Si TFT) and the pixel OLED.

Figure 1(a) shows one circuit for such an energyrecycling AMOLED pixel, which basically consists of a typical two-transistor-one-capacitor AMOLED pixel circuit plus one solar cell. ${ }^{3}$ In this work, the integration of the driving transistor (T2), the OLED, and the solar cell [as highlighted by the dashed line in Fig. 1(a) and illustrated in Fig. 1(b)] was implemented for studying the proposed concept. Each of the devices can be probed to test its functionality by accessing their external contact pads.

The low-temperature poly-Si TFT was fabricated by excimer laser annealing, as described elsewhere. ${ }^{8,9}$ On top of the TFT, a $200 \mathrm{~nm}$ thick $\mathrm{SiN}_{x}$ was deposited by plasma enhanced chemical vapor deposition (PECVD) as an interlayer

\footnotetext{
${ }^{a)}$ Electronic mail: chungwu@cc.ee.ntu.edu.tw

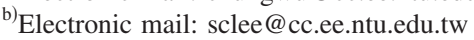

insulator. The deposition of $\operatorname{SiN}_{x}$, was carried out with a $\mathrm{SiH}_{4}$ flow rate of $52 \mathrm{SCCM}$ (SCCM denotes cubic centimeter per minute at STP), a $\mathrm{N}_{2}$ flow rate of 250 SCCM, a substrate temperature of $250{ }^{\circ} \mathrm{C}$, a rf power of $300 \mathrm{~W}$, and a chamber pressure of $90 \mathrm{~Pa}$. Then a $120 \mathrm{~nm}$ thick $\mathrm{Cr}$ was deposited and patterned as the anode of the solar cell. The $p-i-n$ structure of the $a-\mathrm{Si}: \mathrm{H}$ solar cell was grown by PECVD, sequentially including a $15 \mathrm{~nm}$ thick $p^{+} a-\mathrm{Si}: \mathrm{H}$ layer (doped with $480 \mathrm{ppm}_{2} \mathrm{H}_{6}$ ), a $350 \mathrm{~nm}$ thick undoped $a$-Si:H layer, and a $10 \mathrm{~nm}$ thick $n^{+} a$-Si:H layer (doped with $530 \mathrm{ppm} \mathrm{PH}_{3}$ ). A $120 \mathrm{~nm}$ indium tin oxide (ITO) was then sputtered at room temperature on $n^{+} a-\mathrm{Si}: \mathrm{H}$ as the cathode of the solar cell and then was patterned by wet etching. The room-temperature processed ITO gave a sheet resistance of $\sim 100 \Omega$ /sq. Subsequently, the $p-i-n$ structure was patterned by reactive ion etching. After the completion of the solar cell, a $330 \mathrm{~nm}$ low-temperature $a-\mathrm{SiN}_{x}$ was deposited by PECVD as an interlayer insulator. This $\operatorname{SiN}_{x}$ was deposited with a $\mathrm{SiH}_{4}$ flow rate of $10 \mathrm{SCCM}$, a $\mathrm{NH}_{3}$ flow rate of 3 SCCM, a $\mathrm{N}_{2}$ flow rate of 197 SCCM, a substrate temperature of $100{ }^{\circ} \mathrm{C}$, a rf power density of $0.36 \mathrm{~W} / \mathrm{cm}^{2}$, and a chamber pressure of $120 \mathrm{~Pa}^{9}{ }^{9}$ The $\mathrm{SiN}_{x}$ was then patterned to define a contact hole to the TFT. A $600 \mathrm{~nm}$ ITO was then sputtered at room temperature as the transparent anode of the OLED and for interconnection to the driving TFT. The ITO electrode was treated with UV ozone and was spin coated with the conducting polymer polyethylenedioxythiophene:polystyrene sulfonate (PEDT:PSS) as the hole-injection layer. ${ }^{10}$ Finally, various layers of the top-emitting OLED were deposited by thermal evaporation.

The structure of the top-emitting OLEDs is ITO $(600 \mathrm{~nm}) / \mathrm{PEDT}: \mathrm{PSS} \quad(20 \mathrm{~nm}) / \mathrm{NPB} \quad(40 \mathrm{~nm}) / \mathrm{Alq}_{3}$ : rubrene $(20 \mathrm{~nm}, 1 \mathrm{wt} \%) / \mathrm{Alq}_{3}(40 \mathrm{~nm}) / \mathrm{LiF}(0.5 \mathrm{~nm}) / \mathrm{Al}$ $(1 \mathrm{~nm}) / \mathrm{Ag}(20 \mathrm{~nm}) / \mathrm{ZnSe}(30 \mathrm{~nm})$. The OLED has an effective device area of $500 \times 500 \mu \mathrm{m}^{2}$. Organic layers in sequence consist of $N, N^{\prime}$-di(naphthalen-1-yl)$N, N^{\prime}$-diphenyl-benzidine (NPB) as the hole-transport layer, tris-(8-hydroxyquinoline) aluminum(III) $\left(\mathrm{Alq}_{3}\right)$ (doped with rubrene) as the emission layer, and $\mathrm{Alq}_{3}$ as the electron transport layer. ${ }^{11}$ The $\mathrm{LiF} / \mathrm{Al}$ interface facilitates electron injection, ${ }^{12}$ while thin $\mathrm{Ag}$ layer remains highly conductive 
(a)

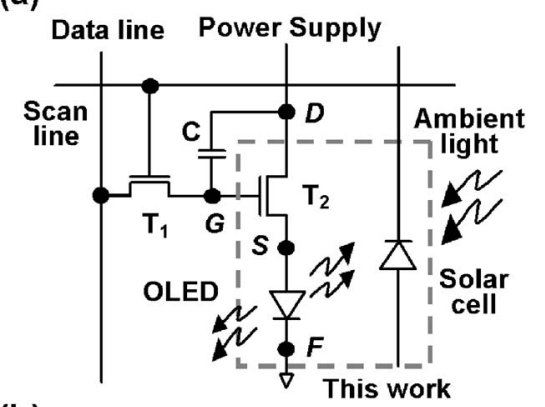

(b)

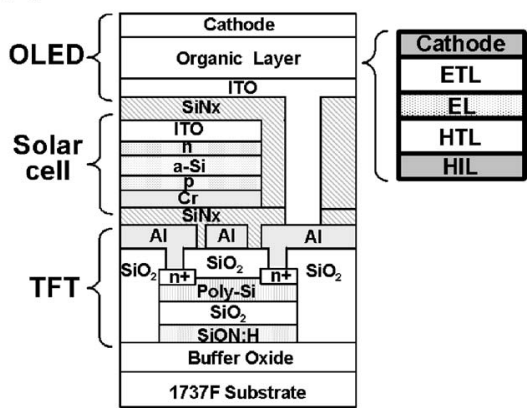

FIG. 1. (a) Schematic circuit diagram of the energy-recycling AMOLED pixel. (b) The schematic diagram showing the structure of the implemented integration of a polycrystalline silicon TFT, an $a-\mathrm{Si}: \mathrm{H} p-i-n$ solar cell, and a top-emitting OLED.

for a semitransparent cathode with relatively low optical absorption. ${ }^{7}$ Finally, a $30 \mathrm{~nm}$ high-index $\mathrm{ZnSe}(n=2.5-2.7)$ was utilized for tuning the optical properties of the semitransparent cathode and the whole structure. ${ }^{7}$ Figure $2(a)$ is a photo showing the fabricated sample under testing, in which the small bright spot is emission of the OLED under the TFT driving. Figure 2(b) is a closer view of the pixel area and the layout, and Fig. 2(c) shows the optical micrograph of one pixel.

Figure 3 shows the measured reflection spectrum of the integrated [OLED+solar cell] structure compared with that of a conventional bottom-emitting OLED. It is clearly seen that the reflectance of the integrated [OLED+solar cell] structure is substantially lower than that of the conventional

(a)
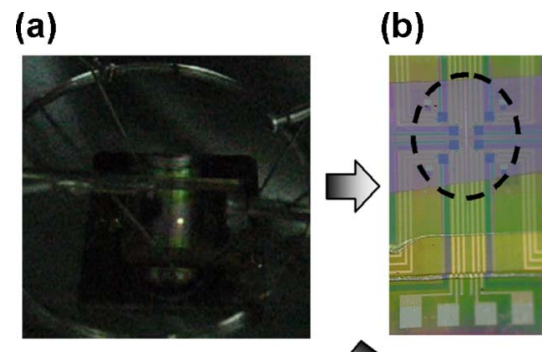

(c)

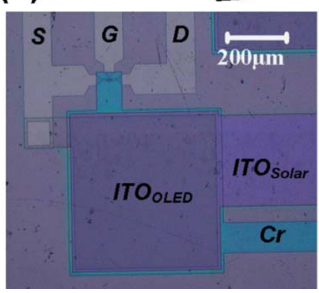

FIG. 2. (Color online) (a) Photo showing the fabricated sample under testing, in which the small bright spot is emission of the OLED under the TFT driving. (b) A closer view of the pixel area and the layout. (c) The optical

micrograph of one complete pixel.
Downloaded 17 Feb 2009 to 140.112 .113 .225 . Redistribution subject to AlP license or copyright; see http://apl.aip.org/apl/copyright.jsp

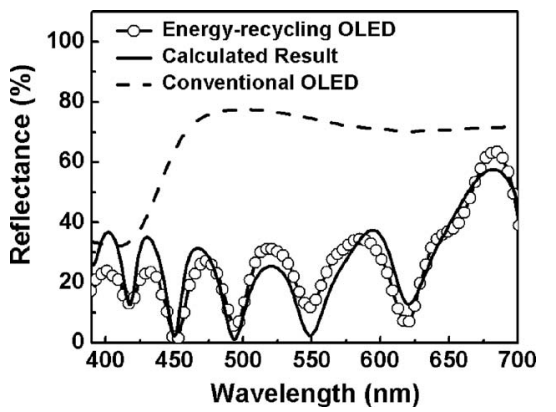

FIG. 3. Measured and calculated reflection spectra of the integrated [OLED+solar cell] structure and the measured reflection spectrum of a conventional bottom-emitting OLED.

OLED. For the integrated device, the average reflectance over the visible-light region is $21 \%$, which the conventional OLED exhibits a reflectance of $\sim 80 \%$ for major visible wavelengths. This lowered reflection of the integrated [OLED + solar cell] structure is clearly visualized as the dark pixel areas in Fig. 2(b) (highlighted by the dashed circle). The measured reflection spectrum of the integrated structure agrees with the calculated one, indicating the reasonable accuracy of the layer thicknesses and optical constants used in the modeling.The somewhat oscillatory behavior in the reflection spectrum of the integrated device is mainly associated with the relatively large thickness of the present [OLED+solar cell] stack. In principle, the reflection spectrum can be further shaped and the overall reflection can be further reduced with optimizing the layer structures and thicknesses. The present pixel structure also has an advantage of blocking the TFT from illumination from either the ambient light or the OLED emission, thus naturally immune to the issue of light-induced leakage currents.

Figure 4(a) shows the output characteristics (under the $n$-type enhancement mode) of the pixel TFT (with the chan-

(a)
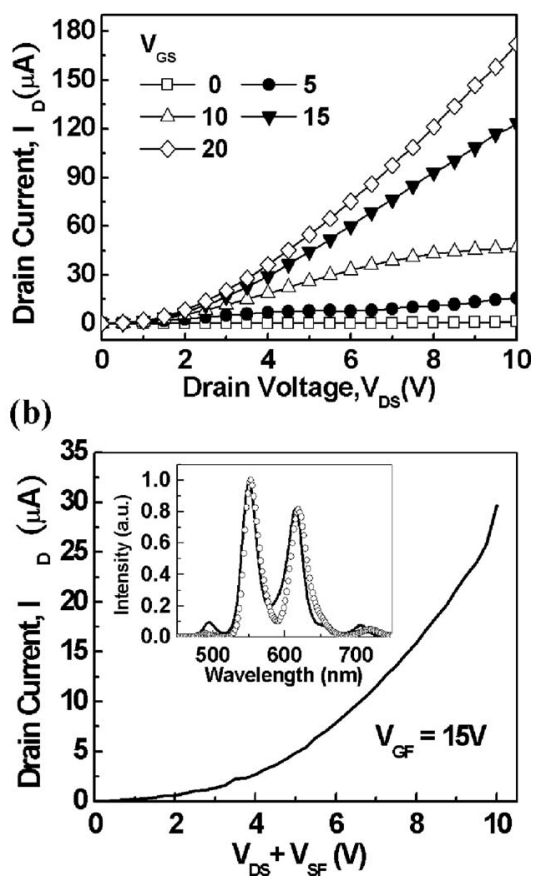

FIG. 4. (a) Output characteristics of the pixel TFT. (b) The TFT drain current (also the current through the OLED) as a function of $V_{\mathrm{DF}}$

$\left(V_{\mathrm{GF}}=15 \mathrm{~V}\right)$. Inset: electroluminescence spectrum of the OLED.
to AlP license or copyright; see http://apl.aip.org/apl/copyright.jsp 

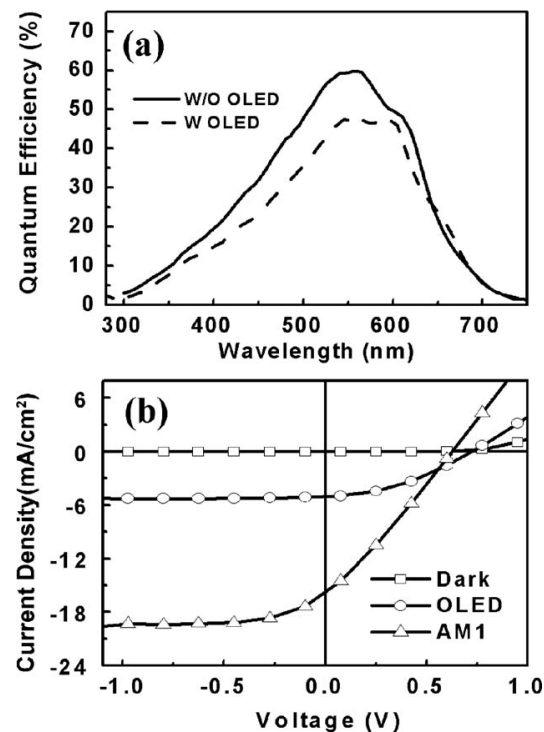

FIG. 5. (a) Spectral responses of the integrated $a-\mathrm{Si}: \mathrm{H} p-i-n$ solar cell before (solid line) and after (dashed line) the deposition of OLEDs. (b) The $I-V$ characteristics of the integrated $a-\mathrm{Si}: \mathrm{H} p-i-n$ solar cell in the dark, under the illumination of an AM1 solar simulator (with an intensity of $1 \mathrm{sun} \sim 100 \mathrm{~mW} / \mathrm{cm}^{2}$ ) and under the illumination of the integrated OLED in the pixel (with a driving current of $28 \mu \mathrm{A}$, an externally observed brightness of $\left.\sim 150 \mathrm{~cd} / \mathrm{m}^{2}\right)$.

nel width/ length of $8 / 6 \mu \mathrm{m}$ ) as a function of the drainsource voltages $V_{\mathrm{DS}}$ under various gate-source voltages $V_{\mathrm{GS}}$. Such characteristics correspond to a carrier mobility and a threshold voltage of $20.1 \mathrm{~cm}^{2} / \mathrm{V} \mathrm{s}$ and $4.2 \mathrm{~V}$, respectively. Figure 4(b) shows the TFT drain current (also the current through the OLED) as a function of the drain-ground voltage $V_{\mathrm{DF}}$ (Fig. 1, i.e., $V_{\mathrm{DS}}+$ OLED voltage $V_{\mathrm{SF}}$ ) when fixing the gate-ground bias $V_{\mathrm{GF}}$ (Fig. 1) at $15 \mathrm{~V}$. At $V_{\mathrm{GF}}=15 \mathrm{~V}$ and $V_{\mathrm{DF}}=10 \mathrm{~V}$, a current of $28 \mu \mathrm{A}$ goes through the TFT + OLED path, which corresponds to an OLED current density of $11 \mathrm{~mA} / \mathrm{cm}^{2}$. At this current density, the OLED gave a brightness of $150 \mathrm{~cd} / \mathrm{m}^{2}$ and an electroluminescence efficiency of $\sim 1.5 \mathrm{~cd} / \mathrm{A}$. Inset of Fig. 4(b) shows the measured emission spectrum of OLED (symbol), which matches well with the calculated one (line). The OLED emission spectrum deviates from the intrinsic emission of rubrene, mainly due to optical effects of the integration structure.

Figure 5(a) shows the spectral responses of the integrated $a$-Si:H $p-i-n$ solar cell, before (solid line) and after (dashed line) the deposition of the OLED stack under the zero bias. The spectral responses for both cases are similar except that with the OLED stack, the peak external quantum efficiency (around 550-600 nm) of converting incident photons to collected electrons drops slightly (i.e., from $60 \%$ to nearly 50\%). The slight decrease of the efficiency is mainly due to the absorption through the thin metal cathode of the OLED. Figure 5(b) shows $I-V$ characteristics of the integrated $p-i-n$ solar cell in the dark, under the illumination of an AM1 solar simulator (with an intensity of 1 sun $\sim 100 \mathrm{~mW} / \mathrm{cm}^{2}$ ) and under the illumination of the integrated OLED in the pixel (with a TFT driving current of $28 \mu \mathrm{A}$ and an externally observed brightness of $\sim 150 \mathrm{~cd} / \mathrm{m}^{2}$ ). The integrated solar cell responded to both external illumination and the OLED internal emission, verifying its energyrecycling functionality. Under the illumination of 1 sun, the solar cell exhibits an open circuit voltage of $0.63 \mathrm{~V}$, a shortcircuit current of $16 \mathrm{~mA} / \mathrm{cm}^{2}$, a fill factor of 0.26 , a maximum power (density) of $2.6 \mathrm{~mW} / \mathrm{cm}^{2}$, and a powerconversion efficiency of $2.6 \%$. Under the illumination of the OLED, the solar cell exhibits an open circuit voltage of $0.72 \mathrm{~V}$, a short-circuit current of $5.04 \mathrm{~mA} / \mathrm{cm}^{2}$, a fill factor of 0.39 , and a maximum power (density) of $1.42 \mathrm{~mW} / \mathrm{cm}^{2}$. Using the electromagnetic modeling of the OLED emission we developed previously, ${ }^{13,14}$ the ratio of the downward OLED radiation power (toward the solar cell) to the upward OLED radiation power (toward the air) under the present integrated pixel structure can be calculated to be about 1.4. Due to higher indices of $\mathrm{SiN}_{x}$ and ITO $(n=2.0-2.2)$ compared with air $(n=1.0)$, the OLED radiation tends to be coupled more into the solar cell than into air. Thus by calculating the downward radiation from the externally measured OLED brightness, we calculated the power-conversion efficiency for the solar cell under the OLED illumination to be $\sim 1.5 \%$. With these figures of merit, we estimate that the amount of energy that can be captured upon operating a $2 \mathrm{in}$. AMOLED at $150 \mathrm{~cd} / \mathrm{m}^{2}$ is about $40 \mathrm{~mW}$ (including both ambient and OLED illuminations), while one notices that such an AMOLED consumes a power of $200-300 \mathrm{~mW}$ nowadays. ${ }^{15}$ This present recycled energy appears modest, yet one should notice that there is plenty of room for further improvement.

In summary, we report an AMOLED pixel that has a solar cell inserted between the driving TFT and the pixel OLED. Such an AMOLED pixel structure not only exhibits a reduced reflection (and thus improved contrast) but also is capable of recycling both incident photon energies and internally generated OLED radiation. Such a feature may be of use for portable/mobile electronics.

This work is supported by National Science Council of the Republic of China under the Contract No. NSC95-2221E-002-298.

${ }^{1}$ A. D. Arnold, P. E. Castro, T. K. Hatwar, M. V. Hettel, P. J. Kane, J. E. Ludwicki, M. E. Miller, M. J. Murdoch, J. P. Spindler, S. A. Van Slyke, K. Mameno, R. Nishikawa, T. Omura, and S. Matsumoto, SID J. 13, 525 (2005).

${ }^{2}$ H-K. Chung, K-Y. Lee, and S. Taek Lee, SID J. 14, 49 (2006).

${ }^{3}$ M. Stewart, R. S. Howell, L. Pires, and M. K. Hatalis, IEEE Trans. Electron Devices 48, 845 (2001).

${ }^{4}$ C. W. Tang and S. A. Van Slyke, Appl. Phys. Lett. 51, 913 (1987).

${ }^{5}$ M.-H. Lu, M. S. Weaver, T. X. Zhou, M. Rothman, R. C. Kwong, M. Hack, and J. J. Brown, Appl. Phys. Lett. 81, 3921 (2002).

${ }^{6}$ H. Aziz, Y.-F. Liew, H. M. Grandin, and Z. D. Popovic, Appl. Phys. Lett. 83, 186 (2003).

${ }^{7}$ C.-J. Yang, C.-L. Lin, and C.-C. Wu, Appl. Phys. Lett. 87, 143507 (2005). ${ }^{8}$ S.-D. Liu and S.-C. Lee, IEEE Trans. Electron Devices 51, 166 (2004).

${ }^{9}$ H.-Y. Chang, C.-Y. Meng, C.-W. Huang, and S.-C. Lee, J. Appl. Phys. 98, 084501 (2005).

${ }^{10}$ A. Elschner, F. Bruder, H.-W. Heuer, F. Jonas, A. Karbach, S. Kirchmeyer, S. Thurm, and R. Wehrmann, Synth. Met. 111-112, 139 (2000).

${ }^{11}$ H. Aziz and Z. D. Popovic, Appl. Phys. Lett. 80, 2180 (2002).

${ }^{12}$ L. S. Hung, C. W. Tang, and M. G. Mason, Appl. Phys. Lett. 70, 152 (1997).

${ }^{13}$ C.-L. Lin, H.-W. Lin, and C.-C. Wu, Appl. Phys. Lett. 87, 021101 (2005).

${ }^{14}$ C.-C. Wu, C.-L. Lin, P.-Y. Hsieh, and H.-H. Chiang, Appl. Phys. Lett. 84, 3966 (2004).

${ }^{15}$ K. H. Lee, S.-Y. Ryu, J. H. Kwon, S. W. Kim, and H. K. Chung, Digest of Technical Papers, 2003 Society for Information Display International Symposium, Baltimore, MD, 2003, p. 104. 